\title{
Five-year follow-up of a cordotomy
}

\author{
Jan J Meeuse $\mathrm{MD}^{1}$, Arnoud $\mathrm{CM}$ Vervest MD PhD², Johannes $\mathrm{H}$ van der Hoeven MD PhD ${ }^{3}$, An KL Reyners MD PhD ${ }^{1}$
}

JJ Meeuse, ACM Vervest, JH van der Hoeven, AKL Reyners. Five-year follow-up of a cordotomy. Pain Res Manage 2008;13(6):506-510.

Percutaneous cervical cordotomy is an invasive procedure to treat severe, opioid-resistant cancer pain. It is usually proposed for patients with a limited life expectancy. As a consequence, objective quantification of the long-term effects of this procedure is lacking. The present report describes a patient who was treated with a right-sided percutaneous cervical cordotomy for refractory cancer pain. Afterward, disseminated seminoma was diagnosed, which was cured with chemotherapy. Five years after the procedure, a qualitative and quantitative evaluation of the long-term effects was performed. Sensory dysfunction was observed in the left side of the body, but no motor neuron or autonomic dysfunction was observed. The influence of these long-term effects on the patient's daily activities was limited.

Key Words: Long-term follow-up; Pain; Percutaneous cervical cordotomy

Tn 1963, Mullan et al (1) introduced percutaneous cervical cordotomy (PCC) for chronic, therapy-resistant pain. It was widely used for chronic pain at first, and was later adapted for cancer pain only.

During PCC, sensory transmission through the lateral spinothalamic tract is interrupted at the C1-C2 level (Figure 1), which disrupts pain fibres from below the $\mathrm{C} 4$ level on the contralateral side.

Immediate pain relief (being pain free without the need for additional analgesics) is achieved in $64 \%$ to $90 \%$ of treated patients (2-4). However, this rate declines to $40 \%$ after two years (2). In part, this is due to the development of deafferentation pain. This pain syndrome, which is difficult to treat, arises in up to $10 \%$ of the patients three months or later after the procedure (5). Based on these data, PCC is advocated for patients with a life expectancy of less than six months (5).

Other complications of PCC are due to unwanted lesioning of structures adjacent to the lateral spinothalamic tract. Reported complications include ataxia, paresis and sympathetic dysfunction (hypotension, Horner's syndrome and bladder dysfunction) (5). Also, the sexual sensitivity in the

\section{Suivi d'une cordotomie à cinq ans}

La cordotomie cervicale percutanée est une intervention effractive visant à traiter les douleurs intenses résistantes aux opiacés. On la propose généralement aux patients dont l'espérance de vie est limitée. C'est pourquoi il est difficile d'en quantifier les effets à long terme. Le présent rapport décrit un patient qui a été traité par cordotomie cervicale percutanée droite pour une douleur cancéreuse rebelle. Par la suite, on a diagnostiqué chez ce patient un séminome diffus qui a pu être traité par chimiothérapie. Cinq ans après l'intervention, on a réalisé une évaluation qualitative et quantitative des effets à long terme de l'intervention. Une dysfonction sensorielle a été observée du côté gauche du corps, mais on n'a noté aucune dysfonction du neurone moteur ou du système nerveux autonome. Ces effets à long terme ont eu peu d'influence sur les activités quotidiennes du patient.

\footnotetext{
${ }^{1}$ Department of Internal Medicine, Section of Palliative Medicine, University Medical Center Groningen, University of Groningen, Groningen;

${ }^{2}$ Pain Clinic, Antonius Hospital, Sneek; ${ }^{3}$ Department of Neurology, University Medical Center Groningen, University of Groningen,

Groningen, The Netherlands

Correspondence and reprints: Dr Jan J Meeuse, Department of Internal Medicine, Section of Palliative Medicine, University Medical Center

Groningen, Post Box 30.001, 9700 RB Groningen, The Netherlands. Telephone 31-(0)50-3619038, fax 31-(0)50-3619069,

e-mailj.j.meeuse@int.umcg.nl
} 
at $95^{\circ} \mathrm{C}$ over $15 \mathrm{~s}$ using a JK4 lesion generator (NeuroTherm, United Kingdom). Further diagnostic workup revealed a stage IIC seminoma. With chemotherapy that consisted of four cycles of carboplatin, vincristine and cyclophosphamide, complete remission was achieved.

\section{METHODS}

The function of the lateral spinothalamic tract and its adjacent tracts was evaluated by interviewing the patient, performing a physical and clinical neurological examination, and performing neurophysiological and autonomic function tests, as well as magnetic resonance imaging (MRI) of the spinal cord at the C1-C2 level.

\section{Neurophysiological tests}

To evaluate the efficacy of the PCC, the warm-cold discrimination threshold was assessed because temperature and pain sensation follow the same central pathway.

The temperature discrimination threshold was quantified using the MSA Thermotest (Somedic, Sweden). Testing was performed on fixed locations of the skin - the lateral side of the foot, palmar side of the hand and lateral side of the face. The temperature of the Peltier element was gradually increased or decreased. The patient pressed a button if he perceived a difference in temperature; the mean of five consecutive warmcold differences was taken as the warm-cold discrimination threshold.

Somatic sensation (such as touch) is mediated by the anterior spinothalamic tract (Figure 1, tract 3b), which is anatomically adjacent to the pain and temperature pathway. The function of the anterior spinothalamic tract was studied using a Touch-Test kit (North Coast Medical Inc, USA). This test consists of 20 different Semmes-Weinstein monofilaments with different buckling forces, ranging from $0.008 \mathrm{~g}$ to $300 \mathrm{~g}$. The touch perception threshold is defined as the lowest perceived buckling force.

Discriminative touch and vibration sense are mediated by the ipsilateral dorsal column (Figure 1, tracts $1 \mathrm{a}$ and 1b). Vibration perception was quantified on the second digit of both hands and on the lateral malleolus of both feet, using a Vibrameter (Somedic, Sweden). The vibration amplitude of the probe was steadily increased until the subject perceived the vibration (the vibration perception threshold). Also, the discriminative touch was tested, determining the two-point discrimination threshold.

Because diabetic and chemotherapy-induced neuropathy are symmetrical, all of these tests were performed on both sides of the patient to discriminate between the effects of the PCC and other possible causes of neuropathy.

\section{Cardiovascular autonomic function tests}

The reticulospinal fibres (Figure 1, tract 6b), which transmit sympathetic outflow, are located near the spinothalamic tract (11). Cardiovascular autonomic function was assessed during deep metronomic breathing, the Valsalva manoeuvre, standing up and the cold pressor test (12).

\section{MRI scanning}

To visualize the anatomical location of the lesion, MRI scanning was planned.

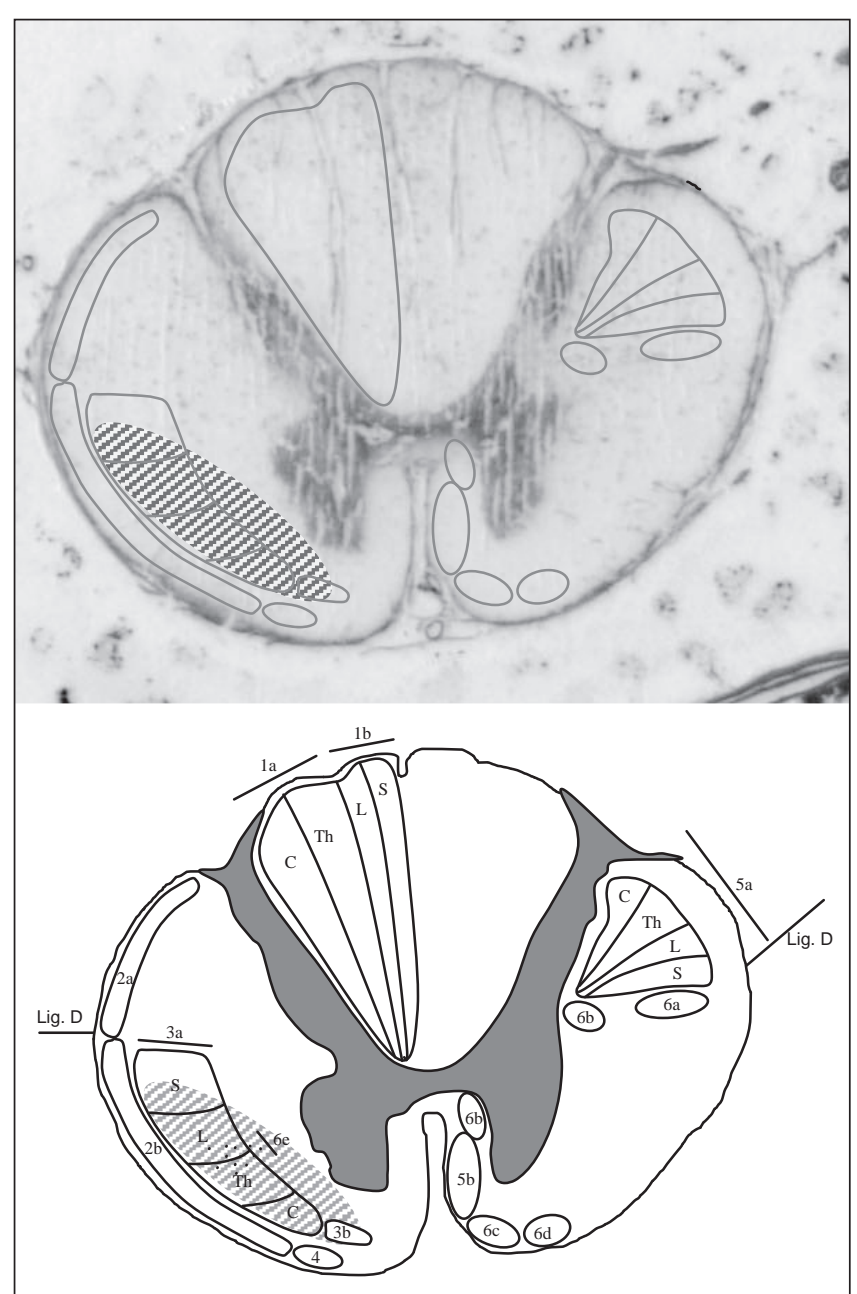

Figure 1) A microtome section of the spinal cord at the C1-C2 level (adapted with permission from reference 18). Ascending afferent pathways (numbers 1 to 4) and descending efferent pathways (numbers 5 and 6) are schematically shown. The striped area is the supposed lesion due to percutaneous cervical cordotomy. 1 Dorsal column (conscious proprioception and discriminative touch): 1 a Fasciculus cuneatus, $1 b$ Fasciculus gracilis; 2 Spinocerebellar tracts: 2 a Tractus spinocerebellaris posterior (contralateral proprioception), $2 b$ Tractus spinocerebellaris anterior (proprioception and exteroception, largely from the opposite lower extremity); 3 Anterolateral system: 3 a Tractus spinothalamicus lateralis (pain and temperature sensation), $3 b$ Tractus spinothalamicus anterior (somatic sensation, such as touch); 4 Tractus spino-olivaris (proprioception via the olivary nucleus to the cerebellum). Motor and descending pathways (right): 5 Pyramidal tracts: 5 a Tractus corticospinalis lateralis (voluntary movement [fibres from contralateral motor cortex]), 56 Tractus corticospinalis anterior (voluntary movement [fibres from ipsilateral motor cortex]); 6 Extrapyramidal tracts: 6 a Tractus rubrospinalis (flexor muscle tonus), $6 b$ Tractus reticulospinalis (sympathetic outflow), 6c Tractus vestibulospinalis (control of upright position), 6d Tractus olivospinalis (exact function unknown), 6e Tractus reticulospinalis ventrolateralis (autonomic breathing); Somatotrophic organization: C Cervical; L Lumbar; S Sacral; Th Thoracic. Lig. D Ligamentum denticulatum

\section{RESULTS}

\section{Patient history}

The PCC induced immediate, complete analgesia and numbness from segment $\mathrm{C} 4$ to S5 on the left side. Although the 


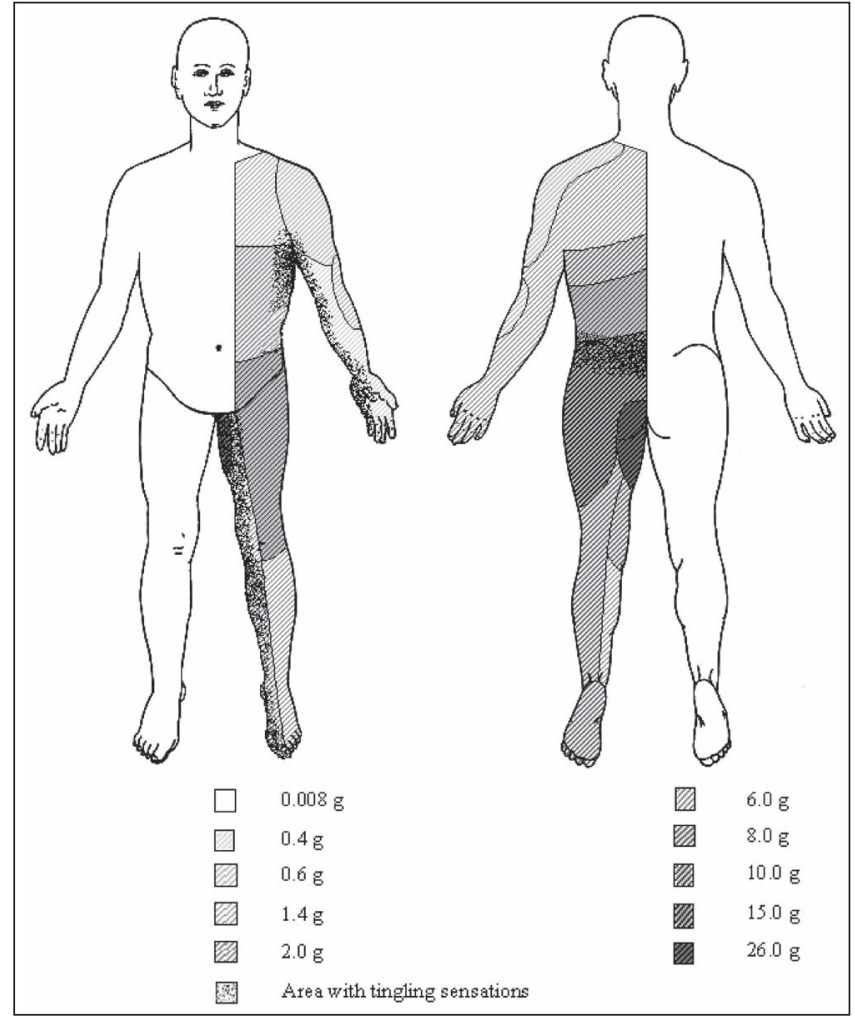

Figure 2) The touch perception threshold was evaluated by using Semmes-Weinstein monofilaments (Touch-Test kit; North Coast Medical Inc, USA). A skin area was probed with a series of monofilaments with increasing buckling forces. The lowest force perceived defined the touch perception threshold. In the spotted areas, tingling sensations were felt

somatic sensory function improved during the first 12 months after PCC according to the patient, there was no full recovery. Warm-cold and pain sensation remained absent, which made the patient unaware of small injuries in the affected area. Wound healing was unremarkable. He was able to perform his daily activities in spite of this sensory dysfunction.

Two weeks after the PCC, tingling sensations in the left arm and leg developed. Although still continuously present (Figure 2), this sensation decreased over time with respect to intensity and the area affected.

Sexual sensation was absent, resulting in diminished sexual pleasure. Erection was obtained with the use of sildenafil. No alteration in bladder function occurred.

\section{Physical examination}

On physical examination, an obese man $(138 \mathrm{~kg}, 186 \mathrm{~cm})$ was seen with a blood pressure of 190/90 $\mathrm{mmHg}$ and a regular pulse rate at 80 beats/min. No Horner's syndrome was observed. A full clinical and neurological examination was unremarkable, apart from nearly absent pinprick perception in the left $\mathrm{C} 4$ to S5 segments. Also, touch and vibration sensations were slightly diminished in this area. Strength and tone of the arm and leg musculature were normal. No atrophy was observed. Furthermore, coordination and reflexes were normal.

\section{Neurophysiological examination (Table 1 and Figure 2)}

The thresholds for temperature and touch perception were elevated in the left $\mathrm{C} 4$ to S5 segments. The vibration threshold
TABLE 1 Neurophysiological tests

\begin{tabular}{lccc}
\hline \multicolumn{1}{c}{ Right } & Left & Normal \pm SD \\
\hline Warm-cold discrimination threshold $\left({ }^{\circ} \mathrm{C}\right)^{*}$ & & \\
Face & 1.0 & 1.4 & $0.9 \pm 0.8$ \\
Thenar & 7.0 & 20.7 & $1.9 \pm 1.1$ \\
Lateral malleolus & 7.7 & 24.5 & $4.2 \pm 3.2$ \\
Vibration perception threshold $(\mu \mathrm{m})^{\dagger}$ & & \\
Hand & 3.4 & 2.5 & $2.6 \pm 1.1$ \\
Foot & 10.0 & 24.3 & $5.2 \pm 2.1$ \\
Stationary two-point discrimination threshold $(\mathrm{mm})^{\ddagger}$ & \\
Arm & 12 & 12 & $42.3 \pm 4.4$ \\
Palm & 5 & 9 & $7.5 \pm 1.3$ \\
Trunk & 12 & 10 & $34.3 \pm 4.4$ \\
Leg & 25 & 25 & $27.1 \pm 3.5$ \\
Foot & 12 & 12 & $22.8 \pm 1.5$ \\
\hline
\end{tabular}

*The temperature of a Peltier element was gradually increased or decreased. The patient pressed a button if he perceived a difference in temperature. The mean of five consecutive warm-cold differences was taken as the warm-cold discrimination threshold. Normal values were derived from Meh and Denislic (19); ${ }^{\dagger}$ The stimulating probe, a $13 \mathrm{~mm}$ diameter plastic cylinder, vibrated at a constant frequency of $120 \mathrm{~Hz}$ and induced sinusoidal displacement of the tested tissue. The application pressure was kept constant at the stimulator's weight of $650 \mathrm{~g}$. The vibration amplitude of the probe was steadily increased until the patient perceived the vibration (the vibration perception threshold). Normal values were derived from Yea-Huey et al (20); ${ }^{\ddagger}$ Assessed by using a Disk-Criminator (AliMed, USA). Normal values were derived from Davey et al (21)

was elevated in the lower extremities, with higher thresholds in the left side. The two-point perception threshold was normal, apart from a slight elevation of the threshold in the left hand.

Cardiovascular autonomic function test (Table 2)

All cardiovascular autonomic function test results were normal.

\section{MRI scanning}

Due to the patient's claustrophobia, it was impossible to obtain adequate imaging of the spinal cord at the C1-C2 level.

\section{DISCUSSION}

Five years after PCC on the right side, sensory disturbances without motor or autonomic dysfunction were found in the left side of the body. Pain and temperature sensations were most affected, but touch and vibration senses were also abnormal.

The long-term effects of the PCC can all be explained by damage to pathways in the spinal cord. According to our investigation, the assumed PCC lesion at the C1-C2 spinal cord level is depicted in Figure 1. Unfortunately, we were unable to prove this assumption with MRI.

The diminished touch perception on the left side of the body suggests involvement of the anterior spinothalamic tract in the lesion. The nearby anterior spinocerebellar (mediating proprioception), reticulospinal (mediating autonomic outflow) and cerebrospinal (mediating voluntary movement) tracts seem unaffected in the present patient because there were no signs of ataxia, disturbed coordination, or autonomic or motor dysfunction. 
Long-term follow-up of a cordotomy

Also, the asymmetry in the vibration perception threshold can be explained by the PCC lesion. Fibres that mediate vibration sense bifurcate when they enter the spinal cord. One branch enters the dorsal column; the other terminates at secondorder neurons in the dorsal horn. Both branches remain ipsilateral. However, at the C1-C2 level, the second-order neurons (originating from the dorsal horn) terminate at neurons in the lateral cervical nucleus. Postsynaptic neurons from this nucleus cross the midline and ascend to enter the medulla (13). At this level, the PCC lesion may have disrupted the vibration sense pathway.

The autonomic function test results were all normal. The increase in blood pressure during the cold pressor test was equal on both sides, although only the right pain- and temperaturetransmitting spinothalamic tract was disrupted during the PCC. This increase in blood pressure is therefore not likely to be centrally induced. It may be a spinal reflex (14) or nonneurogenic vasoconstriction in response to local cooling of the skin (15).

The tingling sensations experienced by the patient may have been an expression of lesions on the second-order neurons of the nociceptive pathway (16).

The patient experienced sexual dysfunction after the PCC. Although absence of sensation in the penis is a known side effect of PCC (6), erectile dysfunction is not. This finding was more likely to have resulted from diabetic neuropathy in our patient.

These long-term effects are comparable with a description in the literature of sensory function evaluated shortly after a PCC procedure (17). Only some studies $(2,9,10)$ describe longterm effects of PCC.

One study comprised 789 patients (2). The data were collected by means of mailed questionnaires and patient selfexamination. One year after the procedure, $25 \%$ of the patients were available for follow-up; the number of patients decreased rapidly toward the eighth year of follow-up. Among these patients, permanent ataxia was found in $3 \%$, sexual dysfunction in $4 \%$ and dysesthesia in $16 \%$.

In other studies addressing the long-term effects of PCC, patient survival is usually short. However, in a retrospective study (9), three of 273 patients survived for five, six and eight
TABLE 2

Cardiovascular autonomic function tests

\begin{tabular}{lll}
\hline & Result & Normal \\
\hline $\begin{array}{l}\text { Deep breathing* } \\
\text { Maximum difference in heart rate } \\
\quad \text { (beats/min) }\end{array}$ & 20 & $>18$ \\
$\begin{array}{l}\text { Valsalva manoeuvre } \\
\quad \text { Valsalva ratio }\end{array}$ & 1.44 & $>1.2$ \\
$\begin{array}{l}\text { Standing up } \\
\quad\end{array}$ & 9 & $<10$ \\
$\quad \begin{array}{l}\text { Drop in blood pressure }(\mathrm{mmHg}) \\
\text { Cold pressor test } \\
\text { Left hand } \\
\quad \text { Increase in blood pressure }(\mathrm{mmHg})\end{array}$ & 17 & $>15$ \\
$\quad$ Right hand \\
$\quad$ Increase in blood pressure $(\mathrm{mmHg})$
\end{tabular}

*The mean difference between the maximum (during inspiration) and minimum (during expiration) heart rate was calculated; ${ }^{\dagger}$ The Valsalva ratio is the ratio between the highest heart rate (during expiration with the glottis open at a pressure of $40 \mathrm{mmHg}$ over $15 \mathrm{~s}$ ) to the lowest heart rate (within $30 \mathrm{~s}$ after the expiratory strain); ${ }^{\ddagger}$ After standing up, blood pooling occurs in the legs, accompanied by a decrease in blood pressure. Normally, this blood pressure drop is less than $10 \mathrm{mmHg}$; ${ }^{\S}$ The patient's hand was held in water at $3^{\circ} \mathrm{C}$ for $3 \mathrm{~min}$, normally resulting in transient peripheral vasoconstriction and an increase in blood pressure. Normal values were derived from Reyners (22)

years after the PCC, without pain or long-term complications. In a third study (10), one patient lived 3.7 years after the procedure. This patient experienced so-called mirror pain (new postcordotomy pain, experienced in the mirror-image area contralateral to the original pain). None of these studies reported quantitative assessment of long-term effects of a PCC.

\section{CONCLUSION}

In the present patient, PCC produced a long-lasting decrease of nociception and temperature sensation without major side effects.

ACKNOWLEDGEMENTS: Dr Jan J Meeuse received financial support from the Comprehensive Cancer Centre NorthNetherlands. The authors are indebted to Professor Dr H Merskey who kindly advised on the manuscript.

\section{REFERENCES}

1. Mullan S, Harper PV, Hekmatpanah J, Torres H, Dobbin G. Percutaneous interruption of spinal pain tracts by means of a strontium 90 needle. J Neurosurg 1963;20:931-9.

2. Rosomoff HL. Percutaneous radiofrequency cervical cordotomy for intractable pain. Adv Neurol 1974;4:683-8.

3. Lahuerta J, Lipton S, Wells JC. Percutaneous cervical cordotomy: Results and complications in a recent series of 100 patients. Ann R Coll Surg Engl 1985;67:41-4.

4. Sanders M, Zuurmond W. Safety of unilateral and bilateral percutaneous cervical cordotomy in 80 terminally ill cancer patients. J Clin Oncol 1995;13:1509-12.

5. Loyd RD, Ball PA, Fanciullo GJ. Surgical procedures for intractable cancer pain. Tech Reg Anesth Pain Manag 2005;9:167-76.

6. White JC. Cordotomy: Assessment of its effectiveness and suggestions for its improvement. Clin Neurosurg 1965;13:1-19.

7. Blaauw G, Zuijderduijn J, Hilvering C. [Percutaneous chordotomy, a method for the treatment of unbearable pain.] Ned Tijdschr Geneeskd 1975;119:59-63.

8. Price C, Pounder D, Jackson M, Rogers P, Neville E. Respiratory function after unilateral percutaneous cervical cordotomy. J Pain Symptom Manage 2003;25:459-63.

9. Stuart G, Cramond T. Role of percutaneous cervical cordotomy for pain of malignant origin. Med J Aust 1993;158:667-70.

10. Crul BJ, Blok LM, van Egmond J, van Dongen RT. The present role of percutaneous cervical cordotomy for the treatment of cancer pain. J Headache Pain 2005;6:24-9.

11. Verlato G, Polati E, Speranza G, et al. Both right and left cervical cordotomies depress sympathetic indexes derived from heart rate variability in humans. J Electrocardiol 2001;34:309-17.

12. Hilz MJ, Dutsch M. Quantitative studies of autonomic function. Muscle Nerve 2006;33:6-20.

13. Gilman S. Joint position sense and vibration sense: Anatomical organisation and assessment. J Neurol Neurosurg Psychiatry 2002;73:473-7.

14. Mizushima T, Tajima F, Okawa H, et al. Cardiovascular and endocrine responses during the cold pressor test in subjects with cervical spinal cord injuries. Arch Phys Med Rehabil 2003;84:112-8.

15. Kellogg DL Jr. In vivo mechanisms of cutaneous vasodilation and vasoconstriction in humans during thermoregulatory challenges. J Appl Physiol 2006;100:1709-18. 
16. Nagaro T, Oka S, Amakawa K, et al. [Classification of post-cordotomy dysesthesia.] Masui 1994:43:1356-61.

17. Lahuerta J, Bowsher D, Campbell J, Lipton S. Clinical and instrumental evaluation of sensory function before and after percutaneous anterolateral cordotomy at cervical level in man. Pain 1990;42:23-30

18. Vervest ACM, Stolker RJ, Ramos LMP, Groen GJ. Anatomical electrode postioning for cervical percutaneous partial rhizotomy. In: Stolker RJ, Vervest ACM, eds. Pain management by radiofrequency procedures in the cervical and thoracic spine; a clinical and anatomical study. Thesis, Utrecht University, 1994:85-98.
19. Meh D, Denislic M. Quantitative assessment of thermal and pain sensitivity. J Neurol Sci 1994;127:164-9.

20. Yea-Huey L, Song-Chou H, Chi-Chao C, Yang-Chyuan C, Sung-Tsang $\mathrm{H}$. Influence of aging on thermal and vibratory thresholds of quantitative sensory testing. J Peripher Nerv Syst 2005;10:269-81.

21. Davey NJ, Nowicky AV, Zaman R. Somatotopy of perceptual threshold to cutaneous electrical stimulation in man. Exp Physiol 2001;86:127-30.

22. Reyners AKL. Cardiovascular autonomic function tests. In: Cardiovascular autonomic function tests: Methodological considerations and clinical application. Thesis, University of Groningen, 2002:9-32. 


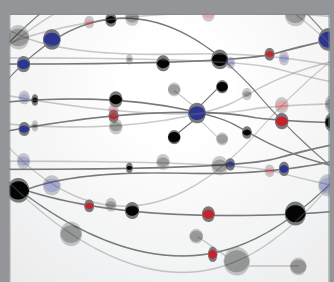

The Scientific World Journal
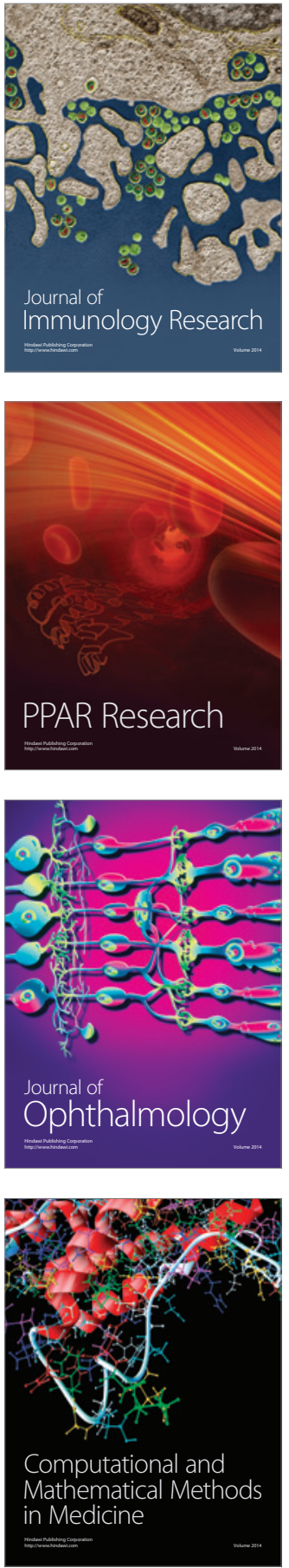

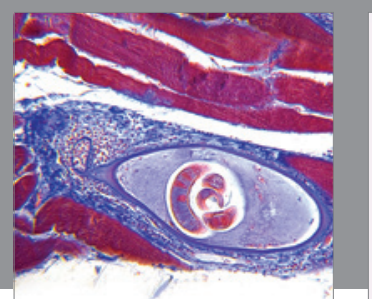

Gastroenterology Research and Practice

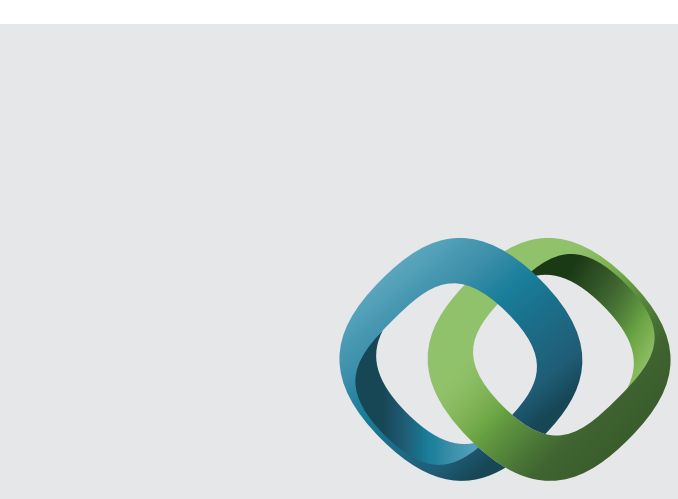

\section{Hindawi}

Submit your manuscripts at

http://www.hindawi.com
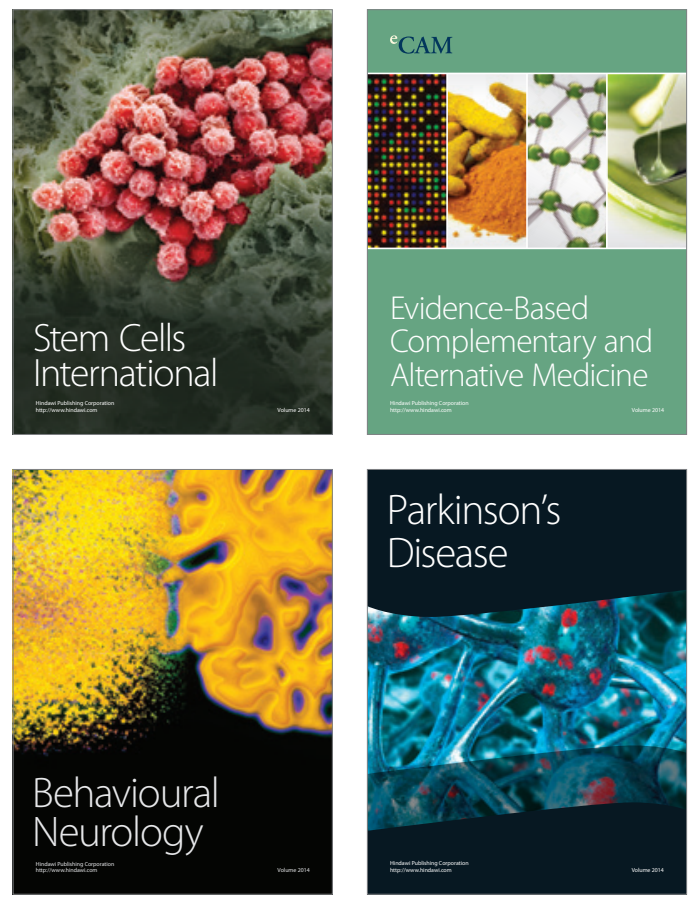
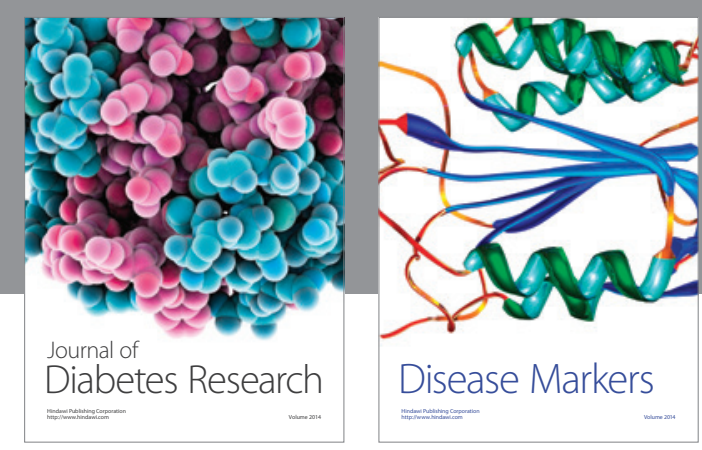

Disease Markers
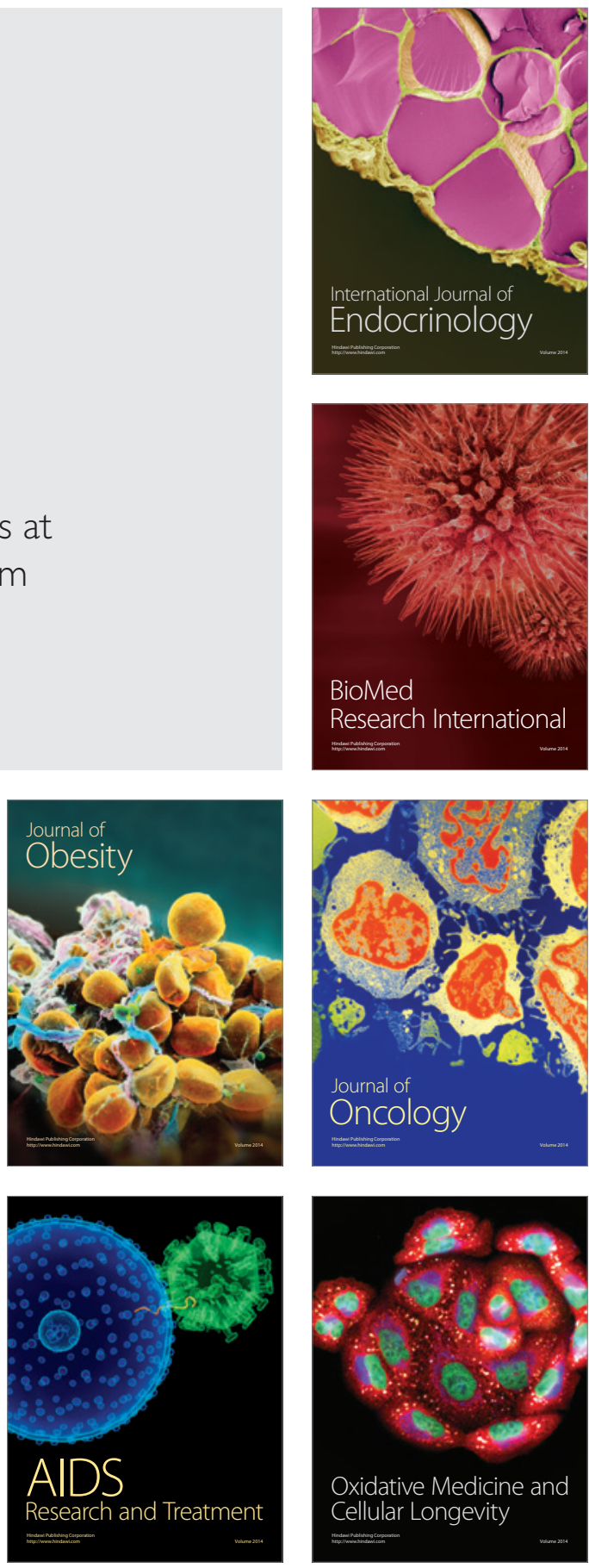